\section{Controvérsias na padronização do middleware de interatividade da TV digital brasileira: democracia técnica à prova do dispositivo
de normatização da inovação Ginga}

Sayonara Leal*

Resumo: O presente texto tem o propósito de reconstruir a cena da controversa normatização do middleware de interatividade da TV digital brasileira - Ginga - cuja arquitetura final resultou na combinação de duas linguagens NCL-Lua (código aberto) e Java-DTV (proprietária). Nosso objetivo é mostrar como, nos termos da democracia técnica, se deu a disputa entre os distintos atores do ecossistema do Sistema Brasileiro da Televisão Digital e Interativa (SBTDi) em torno da coordenação entre digitalização do simbólico, alta definição e interatividade a serviço do mercado e de projetos de inclusão social governamentais pela TV aberta. Interessamo-nos pelos valores e pelas normas postulados por pesquisadores, desenvolvedores, radiodifusores, governo, indústria de software, representações de movimentos pela democratização da comunicação em função do dispositivo de normatização do Ginga, o Fórum SBTVDi. A trajetória do Ginga ilustra como a normatização de inovações são tributárias de tramas sociotécnicas nas quais se vinculam e se desvinculam elementos técnicos e humanos, como se fazem e se desfazem negociações em torno delas. A partir da realização de análise documental e entrevistas semiestruturadas, discutimos a constituição de um objeto-fronteira resultante de embates entre atores que exprimem distintos regimes de engajamentos ao projeto de interatividade aliado à inclusão social e à política industrial no país, propósito inicialmente atribuído ao SBTVDi.

Palavras-chave: Televisão digital interativa. Ginga. Dispositivo de normatização. Democracia técnica. Inclusão social.

\section{Controversies in the standardization of the interactivity}

middleware of the Brazilian Digital TV:

technical democracy to the test of the

normative device of the innovation Ginga

Abstract: The goal of this text is to rebuild the scene of the controversial standardization of Ginga, the interactive middleware of the digital Brazilian TV which final architecture generated the combination of two languages: NCL-Lua (open code) and Java-DTV (owner). Our purpose is to demonstrate how, in the terms of the technical democracy, the dispute among distinct actors of the Brazilian Digital and Interactive TV System (SBTVi) took place between the management of symbolic digitalization, high definition and interaction in service of the market and government's social inclusion projects by open TV. We are interested on the values and norms proposed by researchers, developers, broadcasters, government, software industry, leaders of social movements in favour of
Recebido: 15.11 .18

Aprovado: 13.02.19

\author{
* Sayonara Leal é \\ professora adjunta \\ do Departamento \\ de Sociologia da \\ Universidade de \\ Brasília (UnB), \\ docente do Programa \\ de Pós-graduação \\ em Sociologia da \\ UnB, Brasília, Distrito \\ Federal, Brasil. \\ Orcid: 0000-0001- \\ 9369-1960. \\ <sayonaraleal@ \\ gmail.com>
}


the democratization of the communication concerning the standardization device Ginga, the SBTVi Forum. The history of Ginga exemplifies how the standardization o innovation are associated with social and technical schemes in which technical and human issues get attached and turn apart according to the course of deals. Based on the realization of documental analysis and semi-structured interviews, we discuss the constitution of a border-object output of conflicts among actors who express diverse participations on the interactive project combined with the Brazilian social inclusion and industrial politic, purposes initially attributed to the SBTVi.

Keywords: Digital interactive TV. Ginga. Standardization apparatus. Technical democracy. Social inclusion.

\section{Introdução}

1. Brasil $4 \mathrm{D}$ remete a digital, diversidade, democracia e desenvolvimento. Trata-se de um "aplicativo-base", baseado no NCL-Lua, que funciona no ambiente da TV digital brasileira e gera serviços de informação sobre empregos, saúde, direitos sociais, previdência para famílias beneficiadas pelo Programa Bolsa Família. O projetopiloto do aplicativo foi testado em João Pessoa (PB), em 2013, e na cidade de Samambaia (DF), em 2014 (Leal, Martins \& Condé, 2017).

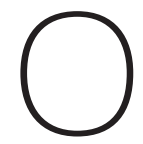
s movimentos em torno da digitalização do simbólico no setor da radiodifusão (operadores de rádio e televisão) têm mobilizado, desde os anos 1990, uma série de práticas informáticas voltadas para arquiteturas de plataformas de comunicação baseadas em tecnologia digital de transmissão dos sinais de sons e imagens. Tais desenvolvimentos proporcionam ganhos em termos de qualidade de vídeo e áudio, aumento da oferta de emissões e novas possibilidades de serviços e aplicações. No Brasil, a questão social ganha relevo na escolha do padrão tecnológico e no design de tecnologias da televisão aberta digital voltadas para usos e aplicações de acordo com necessidades societais locais, mas sem perder conexão com o contexto do mundo global da prática de software. A definição do Sistema Brasileiro de Televisão Digital Interativa (SBTVDi) resulta em um sistema híbrido de tecnologias proprietárias e de código aberto, cuja função de interatividade abre possibilidades para iniciativas de inclusão digital, como o projeto Brasil 4D¹.

A constituição do SBTVDi se dá a partir de, pelo menos, três episódios fundamentais. O primeiro deles é marcado pelo Decreto Presidencial n.o 4.901, de 26 de novembro de 2003, que institui o Sistema Brasileiro de Televisão Digital - SBTVD. Neste documento, são lançados alguns referenciais valorativos para um modelo de TV digital para o país: inclusão social (via interatividade com canal de retorno); mobilidade, portabilidade, multiprogramação (um mesmo canal com diferentes programações, conforme a necessidade dos diferentes públicos), flexibilidade de modelos de exploração e desenvolvimento sustentável (CPQD, 2006). Essas orientações levavam a três cenários possíveis para o SBTVD, que se definem segundo os níveis de agregação de valor aos serviços de TV e de proximidade ou ruptura com o modelo usual da radiodifusão: incremental, diferenciação e convergência.

No cenário incremental não temos rompimento com a cadeia de valor habitual e a digitalização tanto do conteúdo como da transmissão é vista como evento pu- 
ramente tecnológico, com interatividade local e monoprogramação como definição padrão (o que significa um desperdício de espectro disponível). O cenário da diferenciação não sinaliza uma ruptura com o modelo atual, mas prevê a escolha pela emissora entre multiprogramação com definição padrão ou alta definição e interatividade com canal de retorno. O cenário de convergência é aquele que aponta para uma importante mudança no quadro da cadeia de valor da radiodifusão, trazendo diferentes serviços oferecidos por distintos provedores em um ambiente de multiprogramação, portabilidade, interatividade (local e com canal de retorno) e mobilidade (Giansante et alii, 2004; Silva, 2011).

O segundo momento é marcado pelo Decreto n.․ 5.820, de 29 de junho de 2006, que determina a implementação do Sistema Brasileiro de Televisão Digital TerrestreSBTVD-T na plataforma de transmissão e retransmissão de sinais de radiodifusão de sons e imagens, adotando o padrão tecnológico japonês Integrated Services Digital Broadcasting Terrestrial (ISDB-T) para TV aberta/terrestre com as seguintes características: mobilidade, portabilidade, alta definição e interatividade ${ }^{2}$. Essa escolha ${ }^{3}$ se dá após uma longa controvérsia sociotécnica da qual os radiodifusores comerciais saem como os mais favorecidos (Leal, 2015; Vargas \& Leal, 2011; ; Almas, 2013; Maurício, 2012; Silva, 2011; Cruz, 2008). Eles ansiavam pela monoprogramação, pela alta definição do sinal e mobilidade, pelos atributos que levam à manutenção de seu modelo de negócios fundado na publicidade veiculada na grade de programações, dificultando a entrada de novos produtores de conteúdos nesse mercado, além de favorecer um cenário mais incremental para radiodifusão digital.

O terceiro período da implementação do SBTVD se dá entre 2007 e 2012 e nele é notável o controverso processo de definição da arquitetura do middleware brasileiro Ginga, camada de software que permite o desenvolvimento de aplicações interativas para a TV Digital, estabelecendo a interface entre o mundo IP (protocolo usado pela internet) e o mundo broadcast (transmissão de TV aberta), proporcionando a chamada convergência digital.

Na América Latina, o Brasil é o único país que desenvolveu o seu próprio middleware, acoplado ao padrão ISDB-T, o qual já continha, inicialmente, sua própria tecnologia de interatividade, mas o governo brasileiro aspirava desenvolver um software nativo - a parte brasileira do SBTVDi -, o qual foi fruto de pesquisas conduzidas pela Pontifícia Universidade Católica do Rio de Janeiro (PUC-Rio) e pela Universidade Federal da Paraíba (UFPB). O chamado sistema nipo-brasileiro de TVD foi adotado, até março de 2019, por 20 países, incluindo Brasil e Japão, entre as regiões latino-americana, asiática e a africana4 ${ }^{4}$ Usuários do sistema se reúnem em um fórum internacional (Fórum ISDB-T Internacional) para discussões acerca da harmonização de
2. Como postulam Hölbling, Rabl \& Kosch (2008), a interatividade na televisão não é uma novidade. No início dos anos 1960, havia, nos Estados Unidos, programações nas quais telespectadores eram convidados a participar de quiz shows. Na verdade, "o termo televisão interativa (iTV ou ITV) é empregado para a designação de sistemas de televisão nos quais a audiência pode interagir com o conteúdo da televisão. A interatividade na televisão nem sempre significa que o expectador é chamado para mudar o conteúdo de um programa". Os autores classificam sete níveis de interatividade, considerando o contexto da TVD: basic TV, Callin-TV, Parallel TV, Additive TV, Service on demand, Communicative TV e Fully interactive TV.

3. As três normas internacionais mais adotadas para a televisão digital no mundo foram: ATSC (americana, 1993), DVB (europeia, 1993) e ISDB (japonesa, 1999).

4. No quadro de padrões para a interatividade na TVD - middlewares - na Europa, encontramos as normas tecnológicas: HBBTV (França, Alemanha e outros), YouView (Reino Unido) e MHP (Itália). 
normas técnicas visando à interoperabilidade de equipamentos que servem à TVD, tratando também questões sobre implementações locais do middleware de interatividade. A partir da especificação criada pelas universidades brasileiras, qualquer empresa pode desenvolver sua própria versão do Ginga e embarcá-la em TVs. No caso brasileiro, o software Ginga passou por um longo processo de normatização/ padronização dentro do país, o que provocou o retardamento da função interatividade da televisão digital brasileira com impactos para sua viabilidade industrial, comercial e sociopolítica no país.

A padronização de arquiteturas tecnológicas inclina-se a corresponder a configurações específicas da dinâmica entre atores humanos (sociograma) que interferem na estrutura integrada pelos atores não humanos (tecnograma) de um sistema técnico (Latour, 2000). Tal normatização decorre da tradução de valores que uma tecnologia pode incorporar diante de demandas políticas, aspirações do mercado e da indústria, expectativas da sociedade civil e objetivos sociais e técnicos previstos por pesquisadores/conceptores de um padrão tecnológico. Assim, este trabalho está ambientado na discussão sobre dispositivos de normalização de padrões tecnológicos como aparatos sociotécnicos que sediam a coordenação entre atores heterogêneos, destacando limites e perspectivas da chamada "democracia técnica" (Callon, Lascoumes \& Barthe, 2001), em tempos de digitalização do simbólico.

O nosso objeto de estudo é a normatização do Ginga enquanto "objeto-fronteira" que se constrói na interface entre valores industriais/mercadológicos e cívicos/inclusão social. A normalização do Ginga engendra uma controvérsia acerca da arquitetura final desse middleware formada pelas tecnologias Nested Context Language (NCL) e Lua (não proprietária) e JavaDTV (proprietária), ambas resultantes de pesquisas em universidades brasileiras, sendo tanto NCL como Lua inovações nacionais. No caso da linguagem Lua, podemos destacar sua transformação gradual de um projeto altamente local para uma linguagem de programação internacional, sendo uma das 20 linguagens de programação mais populares do mundo. Encontramos seu uso em softwares populares como o Adobe Lightroom e o World of Warcraft (Takhteyev, 2012).

O foco de nossa análise é, justamente, a coordenação de interesses e valores entre atores heterogêneos implicados no desenvolvimento do Sistema Brasileiro de Televisão Digital Interativa (cientistas, emissoras de TV, indústrias de software, indústrias de receptores, governo), os quais se reúnem no espaço de uma entidade civil nacional, sem fins lucrativos, o Fórum do SBTVD-T, integrante do Fórum ISDB-T Internacional, para a formulação das especificações técnicas que regulamentam as implementações do Ginga no Brasil. Estão no centro do problema da normatização 
do middleware a questão política sobre o caráter nacional da tecnologia e a sua integração a um dispositivo de inclusão social, a polêmica sobre o aumento da capacidade tecnológica do Ginga, em termos de interatividade, a partir da inserção da tecnologia Java e, por fim, a questão de pagamentos de royalties a empresas multinacionais proprietárias de licenças para o uso dessa linguagem de programação.

A norma técnica é "dispositivo cognitivo", cuja elaboração cada vez mais se realiza em espaços civis reunindo os atores implicados diretamente em sua regulamentação. Neste sentido, a norma técnica resulta de operações críticas e negociações em instâncias híbridas (fóruns, consórcios), com diferentes representações (público/ privado; humanos/não humanos) em uma atividade coletiva que permite articular uma realidade (econômica, política social, industrial) com uma normatividade amparada num princípio de "bem comum". Por se tratar de um procedimento-chave para o desenvolvimento industrial de produtos e a economia de serviços, a norma técnica pode se constituir em objeto de controvérsias tecnocientíficas, mostrando o caráter social das tecnologias e o caráter tecnológico das sociedades (Kreimer, Thomas, Rossini \& Lalouf, 2004).

A vasta literatura da sociologia da inovação informa-nos que não é necessariamente a natureza de objeto técnico incarnada pelo padrão tecnológico que determina a escolha final de sua arquitetura, mas os dispositivos de interesses mobilizados pela inovação em relação às práticas de todos os atores envolvidos com sua concepção e/ou difusão (Akrich, Callon \& Latour, 1988; 1991; 2006). Mas, a atividade de coordenação entre os diferentes interesses que envolvem a trajetória de uma inovação - a qual se mostra não linear, muito menos regular ou previsível - não pode ser confundida com um evento harmonioso e consensual. Como mostra Latour (1993), as tramas sociotécnicas são reveladoras de como as inovações nascem, evoluem e podem fracassar, de como se fazem e se desfazem negociações em torno delas e como se sucedem entusiasmos e ceticismos ao longo de sua construção. Trata-se de uma empreitada conflituosa em várias etapas, cuja lógica de organização se revela à medida que seguimos os atores nessa trama, a partir da qual as ações (re)produzem relações e estruturas de poder que são reforçadas ou fragilizadas/questionadas no espaço das interações que dão lugar às controvérsias. Ou seja, a relação de forças se estabelece no seio de espaços de negociações a partir de problematizações que podem assumir a forma de uma controvérsia cuja importância sociológica é de nos informar sobre uma situação e suas questões (Lascoumes, 2002; Callon, Yannick \& Lascoumes, 2001).

Do ponto de vista metodológico, o estudo da coordenação de diferentes atores no seio do Fórum SBTVD, seguindo as etapas da controvérsia Ginga (Java-NCL-Lua), 
6. O uso da categoria de ecossistema, neste trabalho, está inspirada na abordagem do ecossistema de software, geralmente aplicada para analisar a indústria de software sob um ponto de vista inspirado em ecossistemas naturais e de negócios, onde se considera não apenas o software em si, mas sua dependência da interação entre elementos humanos e não humanos envolvidos no desenvolvimento de aplicativos, por exemplo (Veiga, Campos, David \& Braga, 2016). permitiu-nos uma reflexividade analítica acerca do fenômeno da normatização do middleware brasileiro como método para chegar a compreender o processo de objetivação conflitual no passado, que deu lugar ao modo de existência do Ginga full como norma técnica, e os desafios que se anunciavam acerca de seu futuro, como a questão de sua adoção e mercantilização.

A análise semântica das entrevistas semiestruturadas com sete categorias de atores (pesquisadores envolvidos no desenvolvimento do Ginga, pesquisadores em conteúdos digitais; desenvolvedores de aplicativos para o Ginga - software livre; desenvolvedores de aplicativos para Java; emissoras que usam o Ginga; empresas de software; representantes da sociedade civil; e governo) (Bardin, 1977) atestou a inteligibilidade das situações a propósito do desenvolvimento e da difusão do middleware, assim como o problema da estabilidade normativa desta tecnologia. Procuramos privilegiar o estudo dos interesses muitas vezes implícitos dos atores em relação às suas expectativas normativas compartilhadas, a partir das quais foi possível retraçar a história e o cenário da controvérsia (Barthe, 2011; Barthe, Akrich \& Remy, 2011; Latour, 2000) e conhecer os valores incorporados à norma originária de um longo processo de negociações acerca de diferentes elementos (inclusão social, código aberto, software livre, linguagem proprietária, manutenção de cadeias de valor, oligopólios e monopólios).

Este trabalho está organizado em três partes, além desta introdução e da conclusão. Na primeira parte, discutimos a normatização como provação fundamental pela qual pode passar uma determinada inovação para se estabilizar. Em seguida, analisamos a controvérsia acerca da Norma Ginga-Java, no espaço do Fórum SBTVD, enquanto dispositivo de normatização e legitimação do middleware. $E$, por último, discutimos, no quadro da democracia técnica, o trabalho de qualificação e valorização das tecnologias distintas que compõem o Ginga pelos atores da padronização, o que irá interferir no resultado da norma.

Notas sobre dispositivos de normatização de tecnologias: qual democracia técnica?

A norma técnica é uma convenção originária da confrontação entre atores reunidos em torno de um dispositivo de negociação com vistas à normatização/padronização de um sistema técnico. Trata-se de um dispositivo cognitivo desenvolvido coletivamente, segundo a coordenação de distintos atores orientados pela noção de um "bem comum", permitindo a expressão de uma racionalidade procedural em face da incerteza crítica à qual são confrontados atores de um dado ecossistema ${ }^{6}$. 
Em termos foucaultianos, um dispositivo é sempre um aparato de agenciamentos de sentidos atrelado ao poder e às suas mais variadas manifestações (política, econômica...), resultando de multiplicidades imbricadas de conteúdos e de expressões governadas por uma instância de poder (Foucault, 1975; 2005; 2008;2015). Ou seja, agenciamentos coletivos de poder como fóruns, consórcios, conselhos, apesar de sua legitimidade, enquanto instâncias decisórias democráticas, podem se remeter seja a uma totalidade abstrata de uma multiplicidade de atores a controlar, seja à ideia abstrata de uma "biopolítica" a serviço da governamentalidade7 de atores em espaços decisórios.

Pensar espaços de normatização de sistemas tecnológicos, neste texto, permite-nos discutir como um dispositivo de coordenação de distintos atores sociais resulta da interdependência de lógicas antagônicas e contratuais vindas, muitas vezes, de instâncias opostas e é, ao mesmo tempo, interpelado tanto por regras do jogo democrático como por embates entre valores que, em situações pragmáticas, se hierarquizam entre si e se objetivam em normas ${ }^{8}$. Nos termos de Dewey (2011), os valores, em função de sua concretude, têm potencial de objetivação, sobretudo quando esses se manifestam no "exercício de inteligência no tratamento de uma situação", referindo-se "àquilo que sustentamos manifestamente", à apreciação/ depreciação direta das qualidades imediatas de um evento, situação ou objeto, por exemplo (Bidet, Quéré \& Truc, 2011). Neste sentido, entendemos que normas (técnicas) decorrem de valores incarnados em sistemas, padrões, modelos tecnológicos que são negociados e se definem no seio de tramas sociotécnicas, por meio das quais "os homens e as coisas trocam suas propriedades e se substituem uns aos outros, é esse o sal dos projetos técnicos" (Latour, 1993: 58).

A literatura socioeconômica sobre a norma, enquanto objeto técnico, vai designá-la de diferentes maneiras, levando em geral em consideração as dimensões textual (a escritura), cognitiva (a definição/designação), valorativa (as justificações) e organizacional (os espaços e seus dispositivos) em torno de sua construção. Para Grignou (2002: 15), a norma é costumeiramente definida como resultado de um trabalho situado de cooperação entre experts, mas redigida, necessariamente, por especialistas em normatização, mantendo em seu processo de elaboração "abertura, transparência, imparcialidade, consenso, coerência e disponibilidade para todos". Para Flichy (1998), em sua abordagem interacionista, o consenso que estabelece a normatização é menos um empreendimento de cooperação e mais o resultado da diplomacia, uma vez que "é preciso aceitar fazer concessões e compromissos". O curso da normatização aparece também atravessado pela imbricação de elementos humanos e não humanos, comportando mais episódios de contradições e de conflitos do que se possa imaginar, sobretudo porque estão no centro da padroni-
7. Na obra de Foucault, encontramos um significativo deslocamento da noção de poder, que vai do poder disciplinar, biopoder, à governamentalidade. Em seus trabalhos, a questão do poder disciplinar se apresentará como absolutamente central entre 1973 e 1975, já a discussão acerca do biopoder recairá no período de 1976 a 1977 e, finalmente, o debate sobre a governamentalidade será destacado a partir de 1978.

8. John Dewey (2011) afirma - como lembram Bidet, Quéré \& Truc (2011) - que não se deve separar normas de valores em função da objetividade. 
zação as "tensões críticas entre os modos de engajamento" dos atores implicados em um determinado projeto pautado em certa noção de "bem comum", em torno da qual as decisões gravitam (Thevenot, 1997).

Neste texto, interrogamo-nos sobre a legitimidade de uma norma e seu processo de elaboração em termos do setor das tecnologias da informação e da comunicação (TICS), o que nos convida a pensar acerca do dispositivo organizacional na normatização de padrões tecnológicos a partir de dimensões (textual-organizacional, valores, epistemes) que impactam o texto e a determinação da norma pronta.

A abordagem textual nos ensina sobre a importância de apreender as circunstâncias precisas que dão forma a um texto normativo, passando pelo espaço de sua construção. Neste sentido, é fundamental a reconstituição de cenários de atores envolvidos no texto final da norma, analisando suas operações discursivas para compreender seus movimentos e as lógicas implicadas nos processos de normatização enquanto domínio da "coordenação sociotécnica" (Mallard, 2000). Assim, cada um dos projetos de norma realiza um agenciamento específico entre as diferentes entidades na instância de um comitê de normatização. Deste ponto de vista, a norma é um dispositivo de coordenação resultante da construção de um acordo e da gênese de informações sobre a tecnologia que estruturam as relações industriais, políticas, mas também mercadológicas. Decorrem da propriedade híbrida desse dispositivo os desafios para alcançar o consenso, pois, a norma, nessa abordagem, é compreendida como documento "capaz" de intervir como vetor de governamentalidade específica nos dispositivos de produção de sentidos e coordenação da ação.

Mallard (2000), bem como Dudouet Mercier e Vion (2006) destacam o processo de escritura da norma sustentando que "a normatização produz objetos operacionais, porque ela se constrói a partir da análise do trabalho realizado" (Dudouet, Mercier \& Vion, 2006: 13). Mesmo reconhecendo a escritura como um processo importante para a compreensão do ato da normatização, esses autores consideram que a dimensão social da norma técnica encontra todo o seu significado nos processos de designação, isto é,

[...] esse processo de designação confere à atividade de normatização sua capacidade de estabelecer uma fronteira social entre aqueles que se prestam a uma prática legítima ou ilegítima, ou simplesmente entre aqueles que podem ou não, devem ou não, lançar-se a uma prática específica (Dudouet, Mercier \& Vion, 2006: 13). 
Neste sentido, os autores valorizam o lugar da normatização nos processos de inovação e na estruturação dos mercados pelo viés da denominação dos elementos que integram uma norma. Esse processo de designação é de caráter semântico (vincula-se a qualificações) e decorre da coordenação entre lógicas técnicas, industriais e mercantis cuja legitimidade do resultado da normatização e do espaço onde ela se desenvolve vem da tensão entre a procura de vantagens competitivas e a dinâmica própria da qualificação dos objetos que esse trabalho supõe (Dudouet, Mercier \& Vion, 2006). Esse procedimento é ainda mais complexo quando se evoca a normatização de padrões no quadro da interoperacionalidade entre diferentes tecnologias, uma vez que isso assume papel fundamental para a formação e a estabilização de novos mercados baseados na comercialização de aplicativos para o audiovisual. Trata-se da coordenação entre normatização nacional e internacional como percursos da monopolização dos formatos de objetos técnicos e, como no caso da televisão digital, da padronização de suas plataformas tecnológicas.

A normatização das tecnologias obedece, assim, a parâmetros técnicos que vêm de outros sistemas tecnológicos, de outros comitês de normatização internacionais (como a União Internacional de Telecomunicações - UIT). As especificidades das normas no setor das TICs são caracterizadas pela coexistência de normas que designam comunidades de produtores e/ou utilizadores distintos quando modalidades de intercomunicabilidade não foram desenvolvidas. A questão do modelo econômico de inserção de tecnologias proprietárias na composição de padrões tecnológicos nesse setor é também um parâmetro importante para a definição de uma norma técnica no espaço de sua padronização.

Graz (2013) salienta as consequências da privatização da norma técnica em instâncias nacionais de normatização (fóruns, consórcios), o que pode ocasionar o pagamento de royalties no caso da inserção de uma norma elaborada visando a um sistema tecnológico dentro de outro. Nesse quadro, Hawkins e Bouillon (2000) falam do papel central assumido pelo Estado no processo de produção de normas no domínio das telecomunicações e do audiovisual. Com a convergência tecnológica nos domínios das TICs, existe uma fragmentação dos organismos e a formação de consórcios industriais e de fóruns envolvidos com a normatização técnica. Isto torna o processo e os espaços/dispositivos da normatização mais complexos, com ambiguidades ocasionadas pela existência de patente depositada para certos produtos. Este locus da construção da norma é, portanto, de interesse fundamental para precisar o padrão e a qualificação dos elementos que formam um artefato técnico, já que a norma é o estado normativo de uma tecnologia/inovação. 
Hawkins (2000) destaca que a padronização é apenas uma das formas, entre outras, de coordenar tecnologias, pois diz respeito a empresas e a organizações que buscam objetivos de desenvolvimento relacionados às TICs. Isto se refere ao tratamento das especificidades do modo de funcionamento dos dispositivos organizacionais criados no setor de radiodifusão e telecomunicações, formados por entidades híbridas, como os fóruns e consórcios. As normas construídas nesses espaços

[...] se apoiam, principalmente, sobre a compatibilidade dos diferentes componentes necessários ao desenvolvimento de um novo produto (CD-ROM, DVD) ou sobre os modos de interoperabilidade no domínio das telecomunicações e das tecnologias da informação [...] (Graz, 2004: 244).

O papel desempenhado pelos consórcios e fóruns no processo de padronização reflete-se na implementação de mecanismos de mobilização dos atores do ecossistema de inovação que ali se encontram. A norma é o dispositivo de mobilização e a ela se dirige todo tipo de dispositivos de interesse que atrai a atenção dos atores da normatização de uma tecnologia. Para Hawkins (2000), o verdadeiro papel da maioria dos consórcios é romper as fronteiras tradicionais entre redes "públicas" e "privadas", enraizadas em um sistema tradicional de padronização, especialmente quando os consórcios e os fóruns estão se movendo em direção a novos mercados audiovisuais. Segundo o autor,

[...] um dos principais objetivos da política de consórcios é, sem dúvida, impedir que as novas tecnologias, que constituem a espinha dorsal do sucesso comercial de todo o setor das TICs, caiam sob o controle exclusivo de certas marcas [...] (Hawkins, 2000: 131).

Do ponto de vista cognitivo, o aumento da força das normas de consórcios e fóruns é explicada pelo acúmulo de conhecimento que é construído coletivamente nesses espaços que carregam a qualidade de serem transepistêmicos, pois expertises e experiências industriais e econômicas são discutidas para resolver um determinado problema.

No que diz respeito ao formato organizacional da construção de normas, nota-se que os consórcios e os fóruns reproduzem um certo número de deficiências, em particular no que diz respeito ao direito de acesso e de influência, que são características dos organismos oficiais (Hawkins, 2000; Graz, 2004). Assim, embora seja um procedimento democrático de definição de normas, o funcionamento de sistemas oficiais de padronização é objeto de críticas. Isto se dá por causa de estruturas já existentes e nelas os diferentes atores estão, às vezes, longe de serem 
iguais em sua participação no processo de padronização, sem mencionar a capacidade de cada um controlar o próprio processo e suas consequências. Além disso, o sistema é sensível a certas manipulações que obedecem a interesses nacionais, grandes empresas ou até mesmo exigências comerciais). Nestes termos, podemos evocar o "papel quase democrático que as normas desempenharam para o bem público na coordenação de tecnologias" (Hawkins \& Bouillon, 2000).

O dispositivo de normatização está, nesse sentido, submetido à provação da democracia técnica (Callon, Lascoumes \& Barthe, 2001), e nele os padrões do consórcio e do fórum são especificações disponibilizadas a todos, mas desenvolvidas por um número mais ou menos limitado de entidades decididas a dar uma resposta coletiva a um determinado problema, especialmente em matéria de inovação em tecnologias avançadas. A fragilidade desses dispositivos organizacionais, no que diz respeito ao alegado caráter democrático para alguns deles, é a ausência dos usuários finais, movimentos da sociedade civil e das pequenas empresas no processo de negociação de um padrão tecnológico, o que torna a normalização um empreendimento mais coletivo e menos institucional (Benezech, 1996).

Consórcios e fóruns são novas formas de ação coletiva que se proliferam no capitalismo contemporâneo, beneficiando-se dos mecanismos participativos implementados pelos governos e organismos oficiais de normatização, no contexto do controle público-social, originando-se da aliança entre tecnicidade, política, economia e direito. Consideramos a norma que resulta da relação de forças nesses espaços como um "objeto-fronteira" resultante da atividade de um dispositivo sociotécnico de padronização/normatização. Como vimos, este objeto híbrido se inscreve em um repertório quádruplo que envolve negociação, designação, justificação e escrita. Nas quatro perspectivas, é possível reverter o projeto inicial da norma, fazer concessões para se adaptar às realidades tecnoeconômicas e para conquistar aliados em todas as dimensões possíveis, incluindo aquela do consumidor final (Flichy, 1998).

Os objetos fronteira

são flexíveis o suficiente para se adaptarem às necessidades e aos anseios específicos dos diferentes atores que os usam e são robustos o suficiente para manterem uma identidade comum (Star \& Griesemer, 1989: 393).

Trata-se de um objeto técnico que é definido na interseção entre mundos diferentes. Eles se adaptam às especificidades da situação e às limitações das partes que os integram. Portanto, a produção de objetos-fronteira é um meio de satisfazer possí- 
veis conjuntos de questões e valores conflitantes, que se expressam no quadro de uma democracia técnica quase sempre limitada.

\section{Dispositivo de normatização do Ginga no quadro da democracia técnica: o Fórum do SBTVD, seus atores e controvérsias}

O Fórum do Sistema Brasileiro de Televisão Digital Terrestre (SBTVD-T) foi criado pelo Decreto Presidencial n.o 5.820/2006, apresentando a mesma norma que regulamenta o padrão japonês como a base técnica de referência do SBTVD-T. Trata-se de um dispositivo não governamental que conta com a presença de agentes do governo, de diferentes ministérios, regido por um conselho deliberativo de 13 participantes com direito a voto. Estes foram representados por radiodifusores, fabricantes de equipamentos de televisão, por pesquisadores de universidades e representantes da indústria de software.

Segundo o estatuto do fórum, seu quadro associativo é composto por três categorias: associados plenos, associados efetivos e associados observadores. Os associados efetivos e os observadores não têm direito a voto, sendo que os primeiros são constituídos por pessoas jurídicas diretamente afetadas pelas decisões tomadas no âmbito do SBTVD brasileiro. Os segundos podem ser pessoas físicas que tenham notório conhecimento dentro do escopo da televisão digital e sejam convidadas por carta formal, via conselho deliberativo, para integrar o fórum. Já os associados plenos são aqueles que dispõem de direito a voto, integrando essa categoria apenas pessoas jurídicas cujas atividades estejam diretamente relacionadas e afetadas pela padronização do sistema brasileiro de televisão digital terrestre. Esses atores representam interesses dos diferentes setores implicados no ecossistema da TV digital brasileira, mais o governo, que não tem direito a voto no conselho.

Os trabalhos no fórum se dividem em quatro módulos: mercado, propriedade intelectual, promoção e técnico. O módulo técnico, que nos interessa aqui, é o responsável pela coordenação de contribuições relativas às especificações técnicas do Sistema Brasileiro de TV Digital e às atividades de pesquisa e desenvolvimento, identificando necessidades de especificação e definindo disponibilidade de soluções técnicas referentes à geração, distribuição e recepção do sistema de TV digital, incluindo alta definição, definição padrão, mobilidade, portabilidade, segurança e autenticação, serviços de dados, interatividade e canais de retorno. Esse módulo também trata da harmonização das especificações técnicas com outras entidades de normatização nacionais e internacionais. Por se tratar do lugar onde 
se discutem e se redigem as normas concernentes ao SBTVD, os participantes desse dispositivo serão aqueles considerados, neste trabalho, como os atores humanos que mais diretamente estiveram implicados com a normatização do Ginga.

Como os integrantes desse grupo foram considerados experts em TV digital, suas deliberações normativas foram, em geral, aceitas pela Associação Brasileira de Normas Técnicas (ABNT), órgão oficial de normatização técnica no país ${ }^{9}$. O fórum revelou-se um locus de exercício de uma "tecnopolítica" (Mitchell, 2002) onde se observam confrontos entre diferentes formas de autoridade (cognitiva, econômica e política) e, ao mesmo tempo, prevalecem as autoridades das políticas de comunicação e de cultura no país, os radiodifusores, que agenciam representações profissionais (em especial, a indústria de software e os agentes dos governos) em favor da legitimação de um projeto incremental e não convergente de TVDi.

\section{Etapas da controvérsia:}

mundos sociais que se revelam confrontados ao Ginga Java

A controvérsia sobre o Ginga começa com a história de uma inovação que resulta de duas propostas de middleware - FlexTV (Ginga-Java) e Maestro (Ginga-NCL-Lua) - desenvolvidas por consórcios liderados por universidades brasileiras, no quadro do Projeto SBTVD, lançado pelo governo federal no primeiro governo Lula para incentivar o desenvolvimento de inovações de integração do Sistemas Brasileiro de Televisão Digital Interativa. A normalização do software de interatividade passa pela problematização acerca de sua arquitetura final formada pelas tecnologias NCL-Lua (não proprietária) e JavaDTV (proprietária), devido ao risco de pagamento de royalties por uso de patentes. O middleware brasileiro traz pelo menos três especificidades importantes para a compreensão de seu contexto de concepção, legitimação e normatização como plataforma tecnológica para interatividade na TV digital brasileira:

i. em primeiro lugar, trata-se de uma inovação concebida em condições de desigualdade social e fratura digital no Brasil;

ii. o Ginga é a primeira tecnologia produzida no país, na área de telecomunicações, reconhecida e indicada para adoção em outros países pela União Internacional de Telecomunicações (UIT); e, por último,

iii. trata-se de um middleware que incorpora o princípio de liberdade e abertura do software livre como tecnologia de código fonte livre e aberto, cuja manipulação é facilitada tanto para desenvolvedores profissionais, vinculados a empresas, como também para aqueles inde-

\author{
9. A ABNT recebe \\ do fórum a redação \\ das especificações \\ técnicas e, em \\ seguida, as submete \\ à consulta pública, \\ antes de publicá-las \\ como regulamento. \\ Quando uma norma \\ técnica é publicada, \\ ela fica 60 dias em \\ consulta pública e \\ se existir alguma \\ manifestação de \\ qualquer brasileiro \\ contra a aprovação \\ da norma, com \\ apresentação dos \\ motivos pelos \\ quais se manifesta \\ negativamente, a \\ ABNT responde a \\ essa negativa. Se a \\ contribuição recebida \\ for acatada pela \\ entidade, o texto \\ volta para consulta \\ por mais 30 dias e \\ somente ao término \\ desse procedimento \\ a norma é aprovada, \\ publicada e entra em \\ vigor.
}


pendentes e "experts leigos" (Collins \& Evans, 2010; Collins \& Pinch, 2010).

O primeiro momento da controvérsia que envolve a normatização do Ginga-NCL-Lua/Java - o que chamaremos aqui como "situação genealógica", no sentido de Barthe et alii (2013) -, se deu entre 2007 e 2008, quando o Fórum SBTVD e o governo brasileiro evocam um problema de barreira comercial com a inserção do Ginga-J ao middleware, em razão do pagamento não desejado pela outorga de licenças para utilização da tecnologia Java TV.

As normas do Sistema Brasileiro de Televisão Digital são divididas em volumes e cada um deles tem uma temática específica: transmissão de vídeo, codificação de vídeo etc. A norma seis, no volume seis, foi dedicada à parte da interatividade, que seria o Ginga. A norma seis tem seis partes principais, seis documentos que foram trabalhados em épocas diferentes, por pessoas que nem sempre estiveram presentes em todas as discussões no Fórum SBTVD. Então, existe um volume da norma que é só do NCL e outro que é dedicado ao Java. Dentro da norma seis, a parte que trata do Java é o volume quatro, ou seja, o Ginga-J (ABNT 15606-4). Como explica o redator da norma,

[...] no meio do caminho para escrever essa norma, com quase tudo pronto, vários conselheiros, fazendo pesquisas sobre o padrão europeu, descobriram que essa parte do padrão, que era herdada pela pesquisa do pessoal do Lavid, do MHP, tinha royalties. Ele era todo baseado num conjunto de royalties, completamente cheio de patentes, regido por uma associação ligada ao DVB europeu.

Na verdade, depois que o consórcio DVB-MHP redigiu a norma de seu middleware (MHP), foram patenteadas diferentes parcelas dessa mesma norma na Europa. Assim, os fabricantes e radiodifusores europeus que queriam usar o MHP tinham de pagar pelas licenças. E essa foi a principal causa para que o MHP não fosse um "sucesso" nos países europeus.

Quando no Fórum SBTVD veio à tona a constatação de que o MHP tinha royalties, os radiodifusores brasileiros reagiram contra a parte Ginga-J, pois não concordaram em pagar pelas licenças. O Ginga-J continha uma série de application programming interface (APIs) e, dentre essas aplicações, havia algumas que pertenciam ao MHP. Um membro da Comunidade Java no Brasil explica que o MHP tem uma série de patentes que são chamadas no mundo de licenciamento de "patente submarino": 
[...] é quando deixam você utilizar a tecnologia e, quando percebem que você está grande o suficiente, vão atrás de você para te cobrar.

Os debates acalorados no fórum levaram o governo a convidar a "dona da tecnologia do Java" - que era, na época, a Sun Microsystems - para conversar com os participantes do fórum e negociar alguma possibilidade de a empresa contribuir na redação de uma nova norma do Ginga-J, diferente do MHP. Para os radiodifusores, a licença na transmissão de uma extensão MHP seria paga em função do número de pessoas que receberiam essa transmissão. Ou seja, quanto maior a audiência, mais as emissoras de TV pagariam pela licença.

Neste momento, os fabricantes de aparelhos de TV se manifestaram contra o embarcamento do Ginga em seus equipamentos, porque viam no middleware um aumento de gastos em sua produção de aparelhos de TV. Esses fabricantes evocavam ainda, em consonância com os operadores da radiodifusão, a imaturidade e o isolamento da tecnologia criada no Brasil. Os fabricantes resistiam ao Ginga como um todo e as emissoras de TV não viam na parte NCL-Lua o potencial de interatividade satisfatório para a TV digital.

\footnotetext{
Havia uma preocupação que o NCL-Lua, por não ser uma linguagem muito conhecida, apesar de ser muito utilizada lá fora (a parte Lua), não tinha o mesmo peso, o mesmo nível de conhecimento que as pessoas tinham do Java, o mesmo número de desenvolvedores. Havia uma comunidade Java muito forte e muito atuante. E havia uma preocupação de algumas emissoras, em especial da Globo, para que a gente não fizesse aplicações que não pudessem ser utilizadas ou aproveitadas em transmissões internacionais (Empresário da indústria de software 3).
}

O segundo episódio da controvérsia - entre os anos de 2008 e 2010 - é marcado pelos efeitos do acordo assinado entre o governo brasileiro e o Fórum SBTVD-T com a Sun, que detinha os direitos do Java à época, para negociar com a empresa uma versão Java livre de royalties. Deste acordo, surge a versão Java-DTV (especificação aberta, reconhecida pela Sun), a especificação técnica base do Ginga-J, que será adotada como parte do Ginga como linguagem de processamento do middleware brasileiro.

O debate fundamental no fórum durante quase dois anos baseava-se, também, sobre o fato de o Brasil adotar ou não a tecnologia Java-DTV, ou se se deveria optar pela tecnologia Globally Executable MHP (GEM). O GEM, presente em algumas versões de middlewares, implica o faturamento de royalties superior àquele presente 
no Java-DTV. Essa nova especificação Java não estaria validada se não houvesse o pagamento de royalties à Sun, que estabeleceu o valor de $€ 0,25$ por equipamento produzido com o Ginga Java-DTV. Neste espaço de discussão, os fabricantes de televisores argumentariam que poderiam acessar a mesma tecnologia a menor custo, a $€ 0,15$ por unidade de equipamento. Neste momento da controvérsia Ginga/Java, os operadores de radiodifusão, os fabricantes de televisores, os pesquisadores, o governo, a comunidade do software livre e a comunidade Java no Brasil interrogaram a Sun sobre os custos elevados para a implementação do Ginga-J, no que concerne aos emissores e receptores de sinais.

Segundo entrevistas com integrantes da Comunidade Sou Java no Brasil e representantes da indústria de software no fórum, a Sun sempre se posicionou contra as patentes criadas com as implementações do MHP. A empresa era favorável que o Java fosse livre de qualquer patente. No entanto, isso não quer dizer que a Sun abriria mão de todos os ganhos com o uso do Java em middlewares para a televisão digital interativa. O interesse da Sun era ter o Java como linguagem integrada a um sistema tecnológico como o Ginga, cujo mercado potencial de produção de apareIhos de televisores no Brasil, à época, ultrapassava as estimativas de todos os países da América Latina.

Para a Sun interessava que o Java fosse amplamente utilizado, pois, para qualquer equipamento embarcar essa tecnologia seria necessário acessar uma virtual machine ou Java Virtual Machine (JVM). Trata-se de um módulo de software que é embarcado e que faz com que tudo que tenha sido escrito utilizando a tecnologia Java possa ser executado. A Sun esperava vender essas licenças de JVM para os fabricantes de equipamentos. Um representante da indústria de software brasileira explica como a Sun se beneficia do Java-DTV:

\footnotetext{
O modelo de negócios deles era o seguinte: você quer escrever uma norma baseada na nossa tecnologia Java, pode escrever, nós não vamos cobrar nenhum royalty, desde que você siga a tecnologia Java. Não pode mexer na tecnologia. Eles sugeriam que não se fizessem extensões para que não se criassem patentes próprias, e que o melhor a fazer era seguir apenas o padrão normal do Java, o "feijão com arroz". "Se você fizer assim, nós não cobraremos royalty para ninguém usar isso, nenhum radiodifusor, mas o fabricante do equipamento vai usar uma JVM que nós vamos vender para eles" (Representante da indústria de software 1).
}

Após as negociações com a Sun, o fórum iniciou reuniões técnicas com a empresa americana e começaram a discutir qual era o Java que se queria para o middleware 
brasileiro. A demanda brasileira era escrever uma norma baseada na linguagem Java que incorporasse o GEM, presente no MHP europeu. Após meses de discussões, chegou-se a um acordo que gerou um contrato assinado entre o fórum e a Sun, no qual essa empresa se comprometia a escrever uma extensão para essa parte da norma do Java, equivalente à europeia, sem cobrança de royalties. Surge, assim, uma comissão no fórum chamada de Ginga-J cuja função era gerenciar o trabalho da Sun, dialogando com os seus técnicos e advogados. O redator da norma lembra a dinâmica de negociações dentro do fórum:

\begin{abstract}
Essa negociação toda, esse debate todo sobre os royalties, sobre o padrão europeu, levou muito tempo. Eram 13 conselheiros no fórum, de diferentes empresas e organismos, mais quatro representantes do governo. É muita gente pra sentar numa mesma mesa e chegar a um acordo. E mais: nenhum deles tinha o menor background técnico em software, com exceção do representante de software. Para a maioria, "falava-se grego". Foi muito complicado e demorou muito tempo.
\end{abstract}

A rediscussão no Forum SBTVD sobre os royalties do Java foi levantada, sobretudo pelos fabricantes de aparelhos de televisão que se uniram àqueles que defendiam o Ginga apenas com o NCL-Lua para operar a interatividade na televisão brasileira, basicamente os pesquisadores das universidades brasileiras e parte da indústria de software. Os argumentos da indústria de aparelho de televisão recaíam sobre os custos menores de produção, embarcando apenas o NCL em seus equipamentos. O Ginga-NCL já estava pronto e implementado por diversos fabricantes desde 2007, mas a parte Java, em função dos problemas de royalties, inexistentes no Ginga-NCL, ficou estagnada. Nesse sentido, a indústria de software defendia que a parte NCL-Lua do Ginga estando normatizada desde de 2007 pela ABNT, permitiria implementar prontamente a interatividade na TV digital.

[...] as empresas de software queriam que a interatividade desse certo. Se a interatividade não existisse, tudo o que eles tinham investido seria zerado. Lucro zero. A norma do NCL já estava pronta e publicada. E muitas empresas de software já tinham implementações prontas do Ginga na parte NCL (Empresário da indústria de software 1 entrevistado).

A problematização da arquitetura do middleware fundamenta-se ainda no caráter nacional e qualitativo (propriedades técnicas e robustez) da tecnologia Ginga-NCL-Lua. De um lado, havia aqueles favoráveis ao Ginga-NCL, pesquisadores das universidades, parte da indústria de software e os fabricantes de televisores, estes dois últimos, por motivos estritamente econômicos, defendiam que o NCL-Lua cumprisse 
com as expectativas funcionais atribuídas ao Ginga e traduzidas em uma tecnologia de ponta.

Primeiro a gente tem que separar o que é Ginga. Java não é Ginga. Ginga é NCL mais qualquer coisa. O Java é o "qualquer coisa" que pode ser aberto ou não. E, exatamente por não ser aberto, o único país que adotou a parte de Java foi o Brasil. Os outros países não adotaram o Java. Ele não é obrigatório. Pra ser Ginga tem que ter o NCL. Não tem que ter mais nada (Pesquisador 4, um dos criadores do Ginga-NCL-Lua).

Sobre a inserção do Java no sistema do middleware, vários pesquisadores entrevistados enfatizaram que se trata de uma linguagem mais apropriada para ambiente de Internet, sobretudo para a proteção de dados bancários, mas para áudio e vídeo seria uma tecnologia demasiadamente "pesada". Além desse argumento contra o Ginga-J, alguns pesquisadores-desenvolvedores de aplicativos interativos para televisão e celulares evocaram que o Java também oneraria a produção de receptores, se pensarmos na inclusão social. Para fazer interatividade local, com baixa conectividade, o Java não seria necessário.

O ponto forte do Java mais destacado neste momento da controvérsia seria a sua grande comunidade de desenvolvedores mundo afora, tendo, somente no Brasil, uma estimativa de 100 mil programadores especializados nessa tecnologia, segundo integrantes entrevistados da Comunidade Java no país. Alguns outros cientistas, assim como parte da indústria de software, defendiam a complementariedade entre NCL-Lua e Java para tornar o sistema tecnológico do Ginga mais robusto. Segundo um pesquisador,

[...] a gente não tem como comparar o NCL com o Java. Sempre ficou bem claro, na comunidade científica, que não dá para fazer esse tipo de comparação, já que um acaba complementando o outro (Desenvolvedor-pesquisador 1 ).

Mas, um pesquisador entrevistado, envolvido no desenvolvimento do middleware, enfatizou o fato de a tecnologia NCL não ter a mesma maturidade e difusão da tecnologia Java, além de defender a "diversidade" de linguagem de programação na composição do middleware brasileiro, ou seja, as tecnologias Java, NCL e Lua. "Isso é muito importante para o espaço interativo. A Internet é interativa porque você tem uma diversidade de ferramentas", comentou o pesquisador 7 .

Os empresários da radiodifusão que não dominavam o debate tecnológico, diferentemente dos demais membros do Fórum SBTVD, não vislumbravam o potencial 
de interatividade do NCL e suas vantagens mercadológicas. O NCL era questionado pelos radiodifusores mesmo havendo provas, realizadas nos laboratórios das universidades brasileiras, de que aplicações interativas baseadas nessa tecnologia funcionavam para a TV aberta e para celulares. O relator da Norma Ginga-J esclareceu:

De um lado da discussão, havia o pessoal favorável ao Ginga, pessoal das universidades, da academia, principalmente da área tecnológica, que falava uma linguagem técnica muito sofisticada, complexa, hermética. Do outro lado, os radiodifusores, os empresários, os engenheiros, que não entendem nada da parte tecnológica. Você consegue imaginar um diálogo entre essas duas partes? Era muito difícil. Eles ficavam se questionando se o NCL não seria mais uma invenção de universitário brasileiro e que tinha muita chance de não dar certo. Quando se olham os números de desenvolvedores, usuários etc., o Java ganha longe, mas a questão não era somente de números. Eles não tinham nenhuma segurança ou garantia de que o Ginga daria certo. $O$ investimento era muito grande e desproporcional à segurança que eles sentiam. Existia, sim, um preconceito muito grande.

Neste momento, os radiodifusores começaram a se interessar pela proposta da interatividade via Ginga, e passaram a se preocupar com o número de desenvolvedores de aplicações interativas na linguagem $\mathrm{NCL}$, muito inferior à quantidade de desenvolvedores em Java no país e no mundo. Um dos pesquisadores que desenvolveram o Ginga-NCL reagiu a essa consideração dos radiodifusores afirmando:

Esse argumento é falso porque, realmente, você tem muito mais programadores em Java, no mundo. Mas não são programadores para TV. Os programadores Java trabalham nas coisas onde o Java é bom. Java é uma linguagem muito boa. Ela só não é boa para TV (Pesquisador 4).

O argumento fundamental dos radiodifusores para defender a permanência do Java no sistema do Ginga foi a consideração de que o Java seria uma tecnologia mais "madura". A preocupação central das redes de TV era com a possibilidade da interatividade começar a funcionar na TV digital brasileira ainda em 2010, sem se desenvolver suficientemente o NCL-Lua. Assim,

[...] eles teriam de contratar muita gente, empresas de software para desenvolver essas aplicações interativas, e eles não queriam ficar "na mão" de uma empresa ou apenas de algumas pessoas que dominavam uma linguagem mais nova. Eles tomaram uma decisão de business, não se tratava de uma decisão levando em conta a tecnologia (Empresário da indústria de software). 
Mesmo ao defender a essencialidade do Java no sistema do Ginga e a insuficiência do NCL para o sucesso da inovação no mercado, os radiodifusores discordavam que no setor havia resistência ao middleware brasileiro. Segundo depoimentos de entrevistados que participaram desse segundo momento da controvérsia, os radiodifusores se articularam com os fabricantes de TV e os dois grupos entraram num acordo pelo voto favorável no fórum pelo Ginga-NCL-Lua + JavaDTV. Nos termos de um pesquisador da PUC/Rio:

Essa é uma questão meramente comercial. Tinha um radiodifusor que queria o Java e, como ele era muito importante, teve a pressão da hora. O Java sempre foi muito polêmico, porque ele não acrescenta nada, torna as coisas mais caras e faz o país remeter royalties pra fora (Pesquisador 4).

Agora, da mesma forma que os radiodifusores se sentaram com os fabricantes e fizeram uma reunião com eles em separado, particular, e esses retornaram e disseram que votariam a favor do Java [...] os radiodifusores sentaram conosco, da indústria de software, e disseram que eles queriam o Java. Nós tentamos demovê-los dessa ideia alegando que, com o NCL, seria mais simples e haveria menos custos. Era mais barato e estava pronto. Os radiodifusores também se tornaram clientes da indústria de software porque eles iam escrever aplicações Ginga de software e, para isso, eles contratariam as empresas de software. Aí eles diziam para a gente que se nós não votássemos a favor do Java, nós não seríamos seus fornecedores. Eles não nos dariam trabalho e nós não ganharíamos dinheiro. Você, indústria de software, vai discutir com uma empresa que é muito maior do que você e ainda vai ser seu cliente? É claro que não. Nós, então, resolvemos votar a favor do Java, implementar essa coisa e absorver todo o atraso. Foi isso o que aconteceu. Nós "entubamos", desculpe o termo.

Em 2010, a votação pela permanência ou não do Ginga-J no Ginga full no conselho deliberativo do fórum resultou em 12 votos a favor e um contra pela permanência do Java. O voto contra foi de um dos representantes da universidade (UFPB), um pesquisador que no passado propôs o Ginga-J, sob a nomenclatura de FlexTV. Um pesquisador da UFPB, envolvido com a concepção do FlexTV, admite que na época que a linguagem foi criada não foi levada em consideração a dimensão econômica pelo uso do Java:

Eu não sei se foi feita essa análise econômica, já que a nossa parte era mais técnica e o nosso principal propósito era atender às necessidades do Brasil, da nossa realidade (Pesquisador-desenvolvedor 2). 
O governo manifestou-se favoravelmente à permanência do Ginga-J no Ginga full, embora não tivessem direito a voto, apenas a voz. Com a definição da arquitetura final do middleware, um executivo do Ministério das Comunicações comentou: "estamos convergindo para um design dominante de tecnologia". Para comentar a participação do governo da normatização do Ginga-J, um pesquisador desabafou: "a radiodifusão no Brasil elege o presidente".

Após a votação no fórum, a especificação Ginga-J, baseada no Java-DTV foi definida, indo para consulta pública pela ABNT. Em abril de 2010, a norma da especificação Ginga-J (ABNT NBR 15606-1:2007/Emenda e ABNT NBR 15606-4) foi aprovada e publicada pela agência de normatização brasileira em Diário Oficial, sendo reconhecida posteriormente pela UIT. Mas, neste momento, não havia nenhum instrumento legal que obrigasse o uso da parte Java para implementações do Ginga completo nos aparelhos de TV. Esse mecanismo de imposição da Norma Ginga (NCL + Java) para quem produzisse aparelhos de televisão no Brasil foi criado com o processo de produção de base (PPB), em 2012. Trata-se de uma portaria interministerial que estabeleceu as regras que obrigaram os fabricantes de televisão LCD/Plasma a embarcarem o Ginga full (Ginga-J e Ginga-NCL) em seus produtos (Brasil, 2012).

O caderno de especificações técnicas do Java já tinha sido publicado em 2010 pela ABNT, quando, em 2011-2012, o tema do Ginga full foi novamente discutido no seio do fórum e no espaço público mediatizado, tornando-se objeto de nova consulta no quadro do fórum. Desta vez, tratava-se do questionamento acerca da exigência legal da tecnologia Java integrada ao middleware para os aparelhos de televisão produzidos no Brasil. O nó dos debates no seio do fórum não decorria da mudança do conteúdo da especificação na norma, era proveniente da obrigação da adoção do Ginga-J, com o Java-DTV, pela indústria de televisão do país. O debate sobre fazer valer a norma oficial e a não fragmentação do Ginga full em suas implementações pela indústria de aparelhos de televisão ${ }^{10}$ e o problema dos valores de licenças exigidas pela Oracle (que comprou a Sun), que detém, atualmente, a propriedade intelectual sobre a máquina virtual Java-Oracle JVM, isto é, o proprietário do direito de uso do Java-DTV e do JVM. Este episódio estamos chamando aqui de terceira fase da controvérsia.

O fato que levou ao novo questionamento do Ginga-J foi quando uma empresa brasileira desenvolveu uma implementação do Ginga, comercializando-o junto aos fabricantes de televisão. Este produto pôde ser distribuído no mercado porque não era possível pagar por seus certificados no Brasil. Um conselheiro do fórum, pesquisador da UFPB, se refere, como parâmetro, ao caso Oracle/Google ${ }^{11}$. Este affaire
10. Os custos para os fabricantes pelo uso do JVM para embarcar o Ginga Java-DTV em seus equipamentos permanecem até o final desta pesquisa como uma caixa preta. O que se sabe é que as negociações que foram feitas com a Sun foram honradas pela Oracle.

11. Na época, foi evocado o famoso caso Google contra Oracle sobre pagamento de royalties do primeiro para o segundo. De fato, "a Oracle processou a Google em agosto de 2010 afirmando que o sistema Android violava sete patentes relativas ao Java, que a sociedade havia adquirido quando comprou a Sun Microsystems. A Oracle reclamou US\$ 2,6 bilhões de danos pela violação alegada" (ver: <http://cio.com.br/ noticias/2012/05/29/ google-vencedisputa-sobrepatentes-do-androidcontra-a-oracle/>). 
levou, uma vez mais, a mudanças de posição sobre a inserção do Java-DTV ao sistema do Ginga entre os participantes do fórum, especialmente entre os industriais de aparelhos de recepção e um pesquisador - nomeadamente, um daqueles que votou a favor do Java em 2009.

Quando o Java era da Sun, eu era a favor da tecnologia. O único inconveniente do Java é que ele é pesado do ponto de vista do cálculo informático. Mas, hoje, este problema está praticamente resolvido. Depois da saída da Sun do negócio, eu comecei a fazer várias questões porque, como eu havia dito, a Oracle é uma sociedade muito mais agressiva que a Sun (Pesquisador 7).

As discussões sobre a Norma Ginga-J foram animadas por dois eventos:

i. a publicação do processo de produção de base (PPB), uma política industrial para encorajar a fabricação no Brasil de aparelhos de TV com Ginga full; e

ii. a publicação na Internet de um manifesto redigido pela Comunidade Java para defender a adoção do Ginga-J nos aparelhos de televisão brasileiros.

O PPB trata das regras para os fabricantes de televisores LCD/Plasma e das especificações do Ginga completo (Ginga-J + Ginga-NCL) como um documento oficial dirigido à indústria de televisores no Brasil. Segundo a Portaria Interministerial n. 187 (Brasil, 2012a), publicada em março de 2012, entre 1 o de julho e 31 de dezembro de 2013, os fabricantes de televisores com tela de plasma deveriam embarcar o middleware em $75 \%$ dos modelos fabricados no país; e esta porcentagem se elevaria a 90\%, a partir do início de 2014 (Brasil, 2012a).

A norma Ginga-J foi aprovada pela ABNT, em 2010, e foi igualmente subscrita pela UIT no quadro da arquitetura do middleware, cuja estrutura é compatível com as características comuns à norma americana (ATSC), à europeia (DVB) e à japonesa (ISDB), ou seja, poderia ser embarcada em qualquer um desses padrões de TVD.

As manifestações na cena pública - favoráveis ou não ao Ginga-J opcional nos televisores - colocavam em evidência o fato de que neste contexto do Ginga todas as empresas que gostariam de vender implementações comerciais do middleware, segundo a ABNT, poderiam ser obrigadas a passar por um processo de certificação dispendioso. Assim, mesmo se o desenvolvedor não faz uso do código da Oracle para fabricar seus aplicativos a partir do Ginga, ele tem o direito de propriedade 
intelectual se passar pelo Test Compatibility Kit (TCK), isto é, se pagar pela certificação ${ }^{12}$. Na época, a indústria de receptores de TV defendeu que o módulo Ginga-J do middleware havia se tornado opcional quando houve implementações, inclusive para os aparelhos DTVi.

Mas, o PPB se traduz em uma política industrial do país para encorajar uma economia baseada no Ginga full e resulta da crítica do governo ao fraco engajamento do setor industrial na implementação da interatividade na TVD brasileira. O PPB foi interpretado por vários atores do ecossistema da TVD do Brasil como estratégia do poder público para fazer face à resistência do setor industrial e adaptar-se às regras de exploração do mercado brasileiro de equipamentos para TVDi. Mas, o documento foi considerado como instrumento insuficiente para a evolução da televisão digital no país, porque também era apontada a falta de engajamento do setor de radiodifusão ao projeto de interatividade que o Ginga incorporava.

Após a publicação do PPB, o retorno da problemática do pagamento de royalties sobre as implementações do Ginga-J no Forum SBTVD levou a Comunidade Java - cujos membros atuam como "porta-vozes" da tecnologia -, a lançar o manifesto Ginga-J: abaixo-assinado a favor de Java e Ginga-J no Padrão Brasileiro de TV Digital.

O manifesto criticava as "mudanças de regras do jogo" após a decisão tomada no processo de normatização do Ginga-J, que determinava este como tecnologia acoplada ao sistema tecnológico Ginga. O documento representava o grupo de utilizadores e desenvolvedores Java no Brasil. Tratava-se de experts em desenvolvimento de soluções utilizando a tecnologia Java e também em políticas de outorga de licenças padronizadas (desde o tempo da Sun e agora com a Oracle), os quais são detentores da sede no Comitê Executivo do Java Community Process. Os desenvolvedores Java organizaram uma petição para a defesa do Ginga-J13 ${ }^{13}$, sustentando o argumento que eles rejeitavam "a tentativa de transformar as regras do jogo após dois anos de investimentos nos produtos Ginga” (Soujava, 2012).

As reações ao manifesto provinham principalmente de pesquisadores universitários implicados na concepção e no desenvolvimento do Ginga, os quais justificaram sua posição a favor da retirada do Java do Ginga full, corroborando uma posição já tomada no momento da votação no seio do fórum que desembocou no formato Ginga-NCL + Ginga-J.
12. Vide: <http:// idgnow.uol. com.br/blog/ circuito/2012/08/20/ licenca-java-pomoda-discordiado-padrao-deinteratividade-da-tvdigital/>

13. Ver: <soujava. org.br>. A Favor de Java e Ginga-J no Padrão Brasileiro de TVDigital - Abaixo Assinado. Ver: <http://soujava.org. $\mathrm{br} /$ servicos/abaixoassinado-ginga-j/>. 
14. Carta do professor Guido Lemos (UFPB) um dos criadores do Ginga-J - em resposta à Petição SouJava. mas dispor de diferentes alternativas seria bem-vindo [...] à condição que isso não crie problemas. NCL e Lua são livres de royalties. Java não está livre de royalties. E mais, a certificação, isto é, o direito de distribuição é controlado por uma empresa [...]. Mesmo para uma empresa imparcial e fiável, é lamentável que um país permita que seu padrão seja controlado por ela (Pesquisador 4).

Eu sou responsável direto pelo uso do Java no Ginga. Eu recomendei o uso pelos mesmos motivos listados por vocês (membros da Comunidade Java) em suas mensagens. Na época (quando o Ginga-J foi criado na UFPB), eu não compreendia o modelo que disciplina o uso da tecnologia Java. O que me alivia neste affaire é que o Google não havia compreendido também e eles foram envolvidos na disputa judiciária que poderia desembocar no pagamento de milhões de dólares a Oracle. Agora que eu tenho uma visão mais clara desse modelo, o que me incomoda muito é que o procedimento para a licença do uso das APIs é controlado por uma só empresa... A questão central é garantir um tratamento não discriminatório para todas as tecnologias de uso inserido na norma (Ginga) $)^{14}$.

A Comunidade SouJava é um ator que desempenha um papel importante em todas as discussões relacionadas à norma Ginga-J, contribuindo mesmo com a elaboração da norma Java-DTV, em 2010. Neste episódio controverso, a Comunidade SouJava teve uma participação política mais destacada: o Manifesto SouJava mobilizou uma rede de desenvolvedores no Brasil que reagiram em seus blogs, em suas redes sociais, com expressões de apoio à permanência da tecnologia Java na arquitetura final do Ginga. Para os representantes SouJava entrevistados, o debate sobre a permanência do Java no sistema Ginga é mais de natureza política do que propriamente técnica: "esta questão é extremamente delicada porque ela é 150\% política".

O fechamento deste terceiro episódio de argumentações acerca da parte Java no Ginga desembocou na manutenção da obrigatoriedade de integração do Java-DTV no middleware brasileiro. Esta decisão foi tomada com um certo consenso construído no seio do fórum, com o consentimento particular de parte dos operadores do setor privado de radiodifusão.

\section{A norma final do Ginga full: um feito da democracia técnica?}

Podemos dizer que o Ginga tornou-se uma política de governo para inclusão digital por meio das possibilidades de uso de sua interatividade na televisão aberta para prestação de serviços públicos (E-gov, E-Educação, E-saúde). O middleware foi tam- 
bém entendido como instrumento estratégico de geopolítica para difusão da tecnologia brasileira em países do Cone Sul e adotado em sistemas de televisão digital de países dessa região (a Argentina, por exemplo, adotou o padrão ISDB-T com Ginga-N$\mathrm{CL}$ ). Por suas características sociotécnicas, que exprimem dimensões sociais e políticas incorporadas ao middleware desde sua concepção em universidades brasileiras, o Ginga foi objeto de incertezas.

As incertezas em relação a uma nova tecnologia estão no centro dos debates controversos acerca dos artefatos tecnológicos, sobretudo porque tanto experts, como agentes públicos, empresários e cidadão comum não podem assegurar o futuro de uma tecnologia. Não podemos prever se ela vai atender a todos os interesses que estão no cerne de sua concepção (Akrich, 1991). No caso do middleware brasileiro, as incertezas foram, sobretudo, de três ordens:

i. tinham natureza tecno-jurídica, quando não havia clareza na política de licenciamentos de soluções proprietárias;

ii. assumiam caráter tecno-político, quando procediam da confrontação entre valores objetivados em regras e qualidades técnicas da tecnologia e sua relação com projetos de políticas públicas governamentais.

iii. eram do tipo tecno-econômica, quando oriundas de um quadro de expectativas de formação de mercados locais associados aos interesses do ecossistema industrial e empresarial dos setores de radiodifusão, telecomunicações e softwares do país.

Essas incertezas em torno dessa tecnologia animaram operações discursivas sobre diferentes dimensões da normatização do Ginga, considerada aqui como "provação" - uma épreuve, no sentido da sociologia pragmática francesa (Barthe et alii, 2013; Callon, Lascoumes \& Barthe, 2001; Boltanski, 1990; Boltanki \& Thevenot, 1991). A normatização, em suas mais variadas dimensões, é épreuve fundamental na trajetória tecnológica do middleware enquanto conjunto de normas técnicas que orienta o desenvolvimentos de dispositivos tecnológicos interativos para a televisão digital brasileira, porque se refere à "capacidade de as pessoas se confrontarem com objetos e de os valorizar..." (Boltanski, 1990), num contexto de controvérsia. Esta se desenvolve a partir das diferentes estratégias discursivas e performativas das operações críticas dos atores implicados no problema gerador da controvérsia. As provações, nesse sentido, são geralmente agenciadas em relação a princípios e valores expressos por atores em situação de incerteza, que engendram uma disputa de argumentos, ideias e normas (Boltanski, 1990). 
Identificamos o dispositivo de normatização do Ginga - o Fórum SBTVD - como espaço civil hibrido onde se manifestam, por excelência, os argumentos que nutrem a controvérsia que, por sua vez, induz a coordenação entre os atores do ecossistema da TV digital brasileira, a representarem as diferentes visões de mundo que negociam a definição do Ginga full. Nesse espaço, manifestam-se laços sociais que sediam a coordenação entre os distintos atores baseados no princípio de uma solidariedade "técnica", que permite o estabelecimento de contratos entre seres que fazem parte de uma negociação e são enquadrados pela lei (Dodier, 1995). Esses laços sociais resultam das ações políticas entre atores humanos em coordenação no espaço híbrido de negociação num contexto de democracia técnica (Callon, Lascoumes \& Barthe, 2001).

Por se tratar de um dispositivo organizacional a operar em termos de democracia técnica, consideramos fundamental três fatores no estudo da normatização do Ginga full:

i. as operações de qualificação/valoração dos atores acerca das duas linguagens distintas que integram o middleware;

ii. as relações de poder que se manifestam no seio do fórum; e

iii. seus agenciamentos e o caráter de democracia técnica atribuída ao dispositivo organizacional;

Do ponto de vista da qualificação e dos valores atribuídos ao middleware brasileiro - em relação ao seu componente NCL-Lua -, os entrevistados o identificam como robusto e capaz de fazer a interatividade funcionar na SBTVD, apesar do déficit de testes em cadeia. Estes resultados vêm de quatro universos diferentes que encontram algumas intersecções entre si:

i. a indústria de aparelhos receptores que, por razões econômicas, em um determinado momento, defendeu Ginga-NCL para integrar seus equipamentos, sem taxas de licença;

ii. a indústria de software, que já tinha desenvolvido as aplicações baseadas na plataforma NCL-Lua, apelou para a aplicação do padrão NCL, regulamentado desde 2007;

iii. os pesquisadores que defenderam a suficiência técnica da parte NCL na arquitetura Ginga para se fazer interatividade ou mesmo aqueles que apoiaram o argumento de complementaridade entre Java e $\mathrm{NCL}$, destacando as qualidades técnicas da tecnologia nacional; e 
iv. os operadores de radiodifusão, após a normalização do Ginga-J, elogiaram o design do Ginga-NCL-Lua e salvaguardaram a arquitetura original do Ginga (Maestro e FlexTV).

A qualificação do Java como linguagem potente e conhecida no mundo de TI é unânime e a tecnologia encontra em seus operadores (Sun/Oracle, Comunidade Java, desenvolvedores de software), somado aos radiodifusores, seus mais fiéis porta-vozes. Esses irão reproduzir os argumentos técnicos positivos que qualificam esta tecnologia em suas justificativas inspiradas pelas lógicas comerciais e industriais (Boltanski \& Thevenot, 1991). Java é, assim, sinônimo de globalização, especialização, experimentação, maturidade, segurança de dados, poder tecnológico e interoperabilidade. Já o NCL-Lua, apesar de ser evocado nas perspectivas das lógicas mercantil e industrial, destaca-se também em relação aos mundos cívico e inspiracional (Boltanski \& Thevenot, 1991).

Do ponto de vista das relações de poder - no caso da padronização do Ginga -, constatamos que a reprodução da autoridade estruturada das operadoras de radiodifusão não deve ser vista como causa dominante para entender o desfecho da normatização, conforme os anseios do Grupo Globo, mas como resultado da coordenação entre os atores heterogêneos que tomaram parte na controvérsia e se engajaram de forma reflexiva ${ }^{15}$ ao projeto dos radiodifusores.

Os testes pelos quais o Ginga passou durante sua normalização resultaram em relações de poder conduzidas por operações críticas dos atores envolvidos na controvérsia. A qualidade dos argumentos desses atores, como vimos, produziu regimes de justificação muito variados sobre a escolha da estrutura da plataforma Ginga. Esses atores se apoiaram em raciocínio técnico, social, político e econômico. Devido à dinâmica entre os atores, os argumentos técnicos dos pesquisadores e da indústria de software sobre o potência da NCL-Lua em relação à interatividade na TVDm - sem a necessidade de Java - perturbava os interesses dos operadores de radiodifusão. De fato, observamos que a conduta desses na escolha do padrão Ginga-J corresponde a uma tendência mundial de preponderância dos argumentos de radiodifusores em questões de padronização no setor. Argumentou-se que o "sucesso" das plataformas interativas na TV digital dependia de todo o seu ecossistema, mas principalmente dos investimentos das emissoras de rádio e TV, pois são os únicos com meios de colocar o público em contato com os dispositivos de interatividade desenvolvidos pelas operadoras e pela indústria de software. No entanto, o caso do Brasil resguarda uma especificidade em relação aos países europeus, em termos de concentração de mídias. Então, não foi evento atípico o fato de as negociações entre representantes da indústria (fabricantes de TVs e empresas de software) e empresas
15. Quando nos referimos, aqui, à reflexividade, estamos nos afiliando ao sentido da competência do ator para mudar o rumo da ação, tal como postulado por Giddens (2010), embora o autor também afirme que a continuidade de práticas presume reflexividade e esta somente é viável graças à continuidade de práticas que as tornem nitidamente as mesmas através do tempo e do espaço (Giddens, 2003). A reflexividade, em Giddens, encontra, assim, dois sentidos fundamentais:

i. reflexividade que se refere à ação (monitoração reflexiva); e

ii. reflexividade como conhecimento e significado (Hay, O’Brian \& Penna, 2010). 
de rádio e TV reforçarem o domínio que exercem sobre a tomada de decisões no setor de radiodifusão no país, desde sempre. O poder político dessas operadoras está justamente no agenciamento desses atores de ações em espaços decisórios como o Fórum SBTVD, jogando com o fato de serem os produtores e veiculadores de conteúdos que oligopolizam uma economia de bens culturais audiovisuais, dependendo deles, em grande parte, os usos do middleware e, portanto, a formação de um mercado para o Ginga.

Em relação ao dispositivo organizacional estudado - que reúne os atores e suas justificações para as escolhas que repercutirão na vida cultural e social das pessoas -, a obtenção de uma norma como objeto cognitivo produzido coletivamente não significa o sucesso da lógica cívica, ou seja, aquela que tem por princípio a "preeminência dos coletivos", a ideia de que todos pertencem a coletividades e o bem comum só se realizaria mediante à subordinação à vontade geral (Boltanski \& Thevenot, 1991) nem, necessariamente, de um modelo deliberativo-participativo equitativo para todos os envolvidos. Como Vion e Dudouet bem nos lembram,

o fato de os padrões técnicos se prestarem menos ao controle central ou que eles se diversifiquem não implica necessariamente o desaparecimento de concentrações econômicas (Dudouet, Mercier \& Vion, 2006: 16)

Da mesma forma, os quadros de coordenação mobilizados pela norma não garantem a estabilidade de uma tecnologia no que diz respeito ao caráter imprevisível de um processo de padronização técnica. A norma permanece enquanto se mantêm e se renovam as relações de poder no seio das quais ela foi engendrada.

\section{Considerações finais}

Em tempos de digitalização do simbólico, sabemos que certas inovações tecnológicas no setor das indústrias culturais perturbam modelos de negócios e ambientes regulatórios, reanimando tensões entre atores portadores de diferentes interesses, representantes do público não estatal, do Estado, do mercado e da indústria, entre outros setores. A perturbação provoca problematizações reunidas, muitas vezes, em controvérsias reveladoras das lógicas de ação que alicerçam associações heterogêneas de atores em torno de um problema a ser solucionado ou estabilizado. Neste sentido, o presente texto teve o propósito de assinalar que a normatização de objetos técnicos - procedimento que o define em sua constituição técnica e humana - não pode ser analisada sem destacarmos a sua complexidade e multidimensionalidade e, muito menos, como simples reflexo de uma racionalidade exclu- 
sivamente técnica. Lançamo-nos, assim, no exercício de reconstruir a cena de uma controvérsia sociotécnica acerca da normatização do middleware de interatividade da TV digital brasileira - Ginga -, cuja arquitetura final resultou na combinação de duas linguagens NCL-Lua (código aberto) e JavaDTV (proprietária) no quadro da digitalização de conteúdos e da transmissão televisiva no Brasil.

Nosso objetivo foi mostrar que a justaposição entre digitalização do simbólico, alta definição e interatividade a serviço do mercado e de projetos de inclusão social governamentais pela TV aberta brasileira passou pela prova da disputa entre distintos agentes do ecossistema do Sistema Brasileiro da Televisão Digital e Interativa (SBTDi), destacando valores e normas postulados por pesquisadores, desenvolvedores, radiodifusores, governo, indústria de software, reunidos no dispositivo de normatização do Ginga, o Fórum SBTVDi.

Interessamo-nos em fazer uma justaposição entre análise tecnológica (a descrição do objeto e de suas propriedades intrínsecas) e análise sociológica do objeto técnico (meios nos quais ele se move e sobre os quais produz seus efeitos). Trata-se da discussão de inovações baseadas na interação social entre um certo número de atores com competências variadas no coração do processo de inovação em seus movimentos de idas e vindas segundo valores e novos dados provenientes dessas trocas (Akrich, 1998).

A norma Ginga (NCL-Lua + Java) - enquanto objeto-fronteira entre dois mundos que compõem o universo sociotécnico do SBTVDi - representa o desfecho de um sistema tecnológico que, do ponto de vista socioeconômico e político, é orientado por um cenário incremental que em nada alterou, até agora, o modelo da cadeia de valor da televisão brasileira. A esperada convergência digital postulada pelos movimentos pela democratização da comunicação, de certa forma conectados com os propósitos cívicos e industriais de pesquisadores de universidades brasileiras e de atores do governo, não se concretizou. A digitalização da TV aberta brasileira e sua interatividade não proporcionou, até o momento, nem inclusão social nem democratização da produção e difusão de nossas riquezas e diversidades simbólicas. O Ginga não alavancou a produção brasileira de software, em parte, pela pouca efetividade de uma política industrial para adoção do middleware em aparelhos receptores e pelo tímido uso da interatividade pela radiodifusão brasileira. O modelo de interatividade de nosso SBTVD engloba um cenário incremental a partir do qual se mantém o status quo da cadeia de valor que sustenta a radiodifusão brasileira, tendo como principal efeito a melhoria na qualidade de sinal na transmissão. 


\section{Referências:}

AKRICH, Madeleine. Les utilisateurs, acteurs de l'innovation. Revue Éducation Permanente, n. 134, p.79-89, 1998.

- Comment sortir de la dichotomie technique/société. Présentation des diverses sociologies de la technique. In: LATOUR, B.; LEMONNIER, P. (Éds.). De la préhistoire aux missiles balistiques: I'intelligence sociale des techniques, p.105-131. Paris: La Découverte, 1994.

- L'analyse sociotechnique dans le processus d'innovation. In: VINCK, D. (Éd.). La gestion de la recherche, p. 339-353. Bruxelles: De Boeck, 1991.

—. De la sociologie des techniques à une sociologie des usages: I'impossible intégration du magnétoscope dans les réseaux cables de première génération. Revue Techniques et Culture, n. 16, p. 83-110, 1990.

AKRICH, Madeleine; CALLON, Michel; LATOUR, Bruno. Sociologie de la traduction: textes fondateurs. Paris: Presses de l'École des Mines, 2006.

À quoi tient le succès des innovations? L'art de l'intéressement, gérer et comprendre. Annales des Mines, n. 11, p.4-17, 1988.

AKRICH, Madeleine; MÉADEL, Cécile. Télévision à la carte: un divorce annoncé. Revue Réseaux, v. 24, n. 39, p. 75-100, 2006.

- Problématiser la question des usages. Sciences Sociales et Santé, v. 22, n. 1, p. 5-20, Mar. 2004.

ALBUQUERQUE, José Augusto Guilhon. Michel Foucault e a teoria do poder. Tempo Social; Rev. Sociol. USP, v. 7, n. 1-2, p. 105-110, Out. 1995.

ALMAS, Almir. Televisão digital terrestre: sistemas, padrões e modelos. São Paulo: Alameda, 2013.

ANGULO, Jorge; CALZADA, Joan: ESTRUCH, Alejandro. Selection of standards for digital television: the battle for Latin America. Telecomunications Policy, v. 35, p. 773-787, 2011. Disponível em: <http://www.sciencedirect.com/science/article/pii/ S0308596111001364>. Acesso: 11 Jan. 2013.

BARDIN, Laurence. Análise do conteúdo. Lisboa: Edições 70, 1977.

BARTHE, Yannick. Les controverses sociotechniques au prisme du Parlement. Quaderni, n. 75, Printemps 2011. Disponível em: <file://C:/Users/sayol/Downloads/ Les_controverses_sociotechniques_au_pris.pdf>. Acesso em: 9 Mar. 2013. 
BARTHE, Yannick; AKRICH, Madeleine; REMY, Catherine. As investigações 'leigas" e a dinâmica das controvérsias em saúde ambiental. Sociologias [online], v. 13, n. 26, p.84-127, 2011. Disponível em: <http://www.scielo.br/scielo.php?script=sci_arttext\&pid=S1517-45222011000100005\&lng=pt\&nrm=iso>. Acesso em. 15 Maio 2014.

BARTHE, Yannick et alii. Les qualités politiques des technologies. Irréversibilité et réversibilité dans la gestion des déchets nucléaires. Tracés. Revue de Sciences Humaines [En ligne], 16 | 2009. Consultado em: 01 Abr. 2014.

—. Sociologie pragmatique: mode d'emploi. Politix, n. 103, p. 175-204, 2013/3.

BENEZECH, Danièle. La norme: une convention structurant les interrelations technologiques et industrielles. Revue d'Économie Industrielle, v. 75, "Normalisation et organisation de l'industrie", p. 27-43, 1르 Trimestre 1996.

BIDET, Alexandra; QUÉRÉ, Louis; TRUC, Gêrome. Ce à quoi nous tenons: Dewey et la formation des valeurs. In: DEWEY, John. La formation des valeurs. Paris: La Découverte, 2011.

BOLTANKI, L. La souffrance à distance: morale humanitaire, médias et politiques. Paris: Métailié, 1990.

BOLTANSKI, LUC; THÉVENOT, Laurent. De la justification: les économies de la grandeur. Paris: Gallimard, 1991.

BRASIL. Presidência da República. Secretaria de Comunicação Social. Pesquisa brasileira de mídia 2014: hábitos de consumo de mídia pela população brasileira. Brasília: Secom, 2014a. Disponível em: <http://www.secom.gov.br/sobre-a-secom/ acoes-e-programas/relatorio-final-da-pesquisa-brasileira-de-midia-2013-2014>. Acessado em: 11 Mar. 2014.

- Secretaria de Assuntos Estratégicos da Presidência da República. Instituto de Pesquisa Econômica Aplicada (Ipea). Pesquisa serviços de telecomunicações. Brasília: Ipea, 2014b. Disponível em: <http://www.ipea.gov.br/portal/images/stories/ PDFs/SIPS/140313_sips_telecomunicacoes.pdf>. Acessado em: 14 Mar. 2014.

—. Ministério das Comunicações. Aviso de seleção pública no 01/2013 - SE/ MC, Projeto Ginga BR.Labs. Programa de Estímulo ao Desenvolvimento do Padrão Nacional de Interatividade da Televisão Digital Brasileira - Ginga Brasil, 3 Maio 2013a. Brasília: MC, 2013.

- Empresa Brasil de Comunicação - EBC. Brasil 4D - Estudo de Impacto Socioeconômico sobre a TV Digital Pública Interativa. Brasilia: EBC, 2013 b. 
- Ministério da Ciência. Tecnologia e inovação. Portaria Interministerial n. 187, de 9 de março de 2012a. Disponível em: <http://www.lex.com.br/legis_23084272_ PORTARIA_INTERMINISTERIAL_N_187_DE_9_DE_MARCO_DE_2012.aspx>. Acessado em: 13 Jan. 2014.

—. Ministério das Comunicações. Programa de Estímulo ao Desenvolvimento do Padrão Nacional de Interatividade da Televisão Digital Brasileira - Ginga Brasil. Portaria n.o 482, de 6 de dezembro de 2012. Brasília: MC, 2012b.

—. Ministério do Desenvolvimento, Indústria e Comércio Exterior. Secretaria do Desenvolvimento da Produção-Substituto. Consulta Pública n.o 8, de 19 de setembro de 2011. Disponível em: <http://www.mdic.gov.br/portalmdic/arquivos/ dwnl_1317060321.pdf>. Acessado em: 24 September 2013.

—. Presidência da República. Decreto n. 5.820, de 29 de junho de 2006.

—. Presidência da República. Decreto n. 4.901, de 26 de novembro de 2003.

CALLON, Michel. Pour une sociologie des controverses technologiques. In: AKRICH, Madeleine; CALLON, Michel; LATOUR, Bruno. Sociologie de la traduction: textes fondateurs, p. 135-157. Paris: Presses de l'École des Mines, 2006a.

- Sociologie de I'acteur reseau. IIn: AKRICH, Madeleine; CALLON, Michel; LATOUR, Bruno. Sociologie de la traduction: textes fondateurs, p. 267-276. Paris: Presses de l'École des Mines, 2006b.

— Le réseau comme forme émergente et comme modalité de coordination: le cas des interactions stratégiques entre firmes industrielles et laboratoires académiques. In: CALLON, Michel et alii. Réseau et coordination, p. 13-64. Paris: Economica, 1999.

. El proceso de construccion de la sociedad: el estúdio de la tecnologia como herramienta para el análisis sociológico. In: DOMÉNECH, Miquel; TIRADO, Francisco Javier (Orgs.). Sociología simétrica: ensayos sobre ciencia, tecnologia y sociedad, p. 143-170. Barcelona: Gedisa Editorial, 1998.

- Réseaux technico-économiques et irréversibilité. In: BOYER, Robert; CHAVANCE, Bernard; GODARD, Olivier (Éds.). Les figures de l'irréversibilité en économie, p. 194-230. Paris: Éditions de L'École des Hautes Études en Sciences Sociales, 1991.

La science et ses réseaux: genèse et circulation des fait scientifiques. Paris: La Découverte, 1989. 
- Some elements of a sociology of translation: domestication of the scallops and the fishermen of St. Brieuc Bay. In: LAW, John (Ed). Power, action and belief: a new sociology of knowledge? Sociological Review Monograph, n. 32, p. 196-233. London: Routledge and Kegan Paul, 1986.

CALLON, Michel; LASCOUMES, Pierre; BARTHE, Yannick. Agir dans un monde incertain: essais sur la démocratie technique. Paris: Les Éditions du Seuil, 2001.

CENTRO DE PESQUISA E DESENVOLVIMENTO EM TELECOMUNICAÇÕES (CPQD). Modelo de referência - Sistema Brasileiro de Televisão Digital Terrestre, 2006. Disponível em: <http://sbtvd.cpqd.org.br>. Acesso em: 05 Mar. 2009.

COLLINS, Harry; EVANS, Robert. Repensando a expertise. Belo Horizonte: Fabrefactum, 2010.

COLLINS, Harry; PINCH, Trevor. O Golem à solta: o que você deveria saber sobre tecnologia. Belo Horizonte: Fabrefactum, 2010.

COMMISSION EUROPÉENNE. LIVRE VERT - Se préparer à un monde audiovisuel totalement convergent: croissance, création et valeurs. Bruxelles, CE, 24 Abr. 2013. Disponível em: <http://eur-lex.europa.eu/LexUriServ/LexUriServ.do?uri=COM:2013:0231:FIN:FR:PDF>. Acessado em: 09 Dez. 2013.

CRUZ, Renato. TV digital no Brasil: tecnologia versus política. São Paulo: Editora Senac, 2008.

CRUZ, Vítor Medina; MORENO, Marcio Ferreira; SOARES, Luiz Fernando Gomes. Ginga-NCL: implementação de referência para dispositivos portáteis. Rio de Janeiro: Telemidia/PUC, 2008. Disponível em: <http://www.telemidia.puc-rio.br/sites/telemidia.puc-rio.br/files/2008_10_vitor.pdf>. Acessado em: 10 Dez. 2013.

DEWEY, John. La formation des valeurs. Paris: La Découverte, 2011.

DUDOUET, François-Xavier; MERCIER, Delphine; VION, Antoine. Politiques internationales de normalisation quelques jalons pour la recherche empirique. Revue Française de Science Politique, v. 56, n. 3, Jun. 2006.

FLICHY, Patrice. La normalisation: un processus d'explication du travail technique. Le cas des caractères du vidéotex. Réseaux, v. 16, n. 87, p. 105-116, 1998.

FOUCAULT, Michel. A verdade e as formas jurídicas. Rio de Janeiro: PUC/Departamento de Letras, 2008.

- Ditos e escritos II: arqueologia das ciências e história dos sistemas de pensamento. Rio de Janeiro: Forense Universitária, 2005. 
- Conversação sem complexos com um filósofo que analisa as "estruturas do poder". In: MOTA, Manoel Barros da (Org.). Ditos e escritos IV: estratégia, poder-saber. Rio de Janeiro: Forense Universitária, 2015 [1978].

- Surveiller et punir. Paris, Gallimard, 1975.

GIANSANTE, M. et alii. Cadeia de Valor. Campinas (SP): Projeto SBTVD, 2004.

GIDDENS, Anthony. O que fazem os sociológos? In: SILVA, Fábio Rodrigues Ribeiro. Realismo e redes: dilemas metodológicos na obra de Anthony Giddens. Tese (doutorado em Sociologia) - Universidade de São Paulo, São Paulo, 2010.

—. A constituição da sociedade. São Paulo: Martins Fontes, 2003.

GRAZ, Jean-Christophe. Quand les normes font loi: topologie intégrée et processus différenciés de la normalisation internationale. Revue Études Internationales. v. 35, n. 2, p. 233-260, Jun. 2004.

GRAZ, Jean-Christophe; NIANG, Nafi (Éds.). Services sans frontières. Mondialisation, normalisation et régulation de l'économie des services. Paris: Collection Presses de Sciences Po, 2013.

CRIGNOU, Thierry. Les structures de la normalisation au niveau national, européen et International. Réalités industrielles, p. 5-10, Nov. 2002.

HAWKINS, Richard; BOUILLON, Anne. Vers une évolution ou vers une disparition de la "démocratie technique"? L'avenir de la normalisation dans le domaine des technologies de l'information et de la communication. Réseaux, v. 18, n. 102, p. 119-137, 2000.

HAY, Colin; O'BRIAN, Martin; PENNA, Sue. Giddens, modernidade e identidade do eu: o "esvaziamento" da teoria social. In: SILVA, Fábio Rodrigues Ribeiro. Realismo e redes: dilemas metodológicos na obra de Anthony Giddens. Tese (doutorado em Sociologia) - Universidade de São Paulo, São Paulo, 2010.

HÖLBLING, Günther; RABL, Tilmann; KOSCH, Harald. Overview of open standards for interactive TV. Studies in Computational Intelligence (SCI), n. 101, p. 45-64, 2008. Disponível em: <www.springerlink.com>. Acessado em: 11 Maio 2013.

KREIMER, P.; THOMAS, H.; ROSSINI, P.; LALOUF, A. (Dirs.). Producción y Uso Social de Conocimientos : Estudios de Sociología de la Ciencia y la Tecnología en América Latina. Buenos Aires : Universidad Nacional de Quilmes Editorial, 2004. 
LASCOUMES, Pierre. De l'utilité des controverses socio-techniques, Chapitre 7. Journal International de Bioéthique, v. 13, n. 2, p. 68-79, 2002. Disponivel em: <http:// www.cairn.info/revue-journal-international-de-bioethique-2002-2-page-68.htm>, Acesso em: 12 Abr. 2012.

LATOUR, Bruno. Ciência em ação. São Paulo: Editora Unesp, 2000.

—. Aramis ou l'amour des techniques. Paris: Éditions La Découverte, 1993.

LEAL, Sayonara. A TV digital interativa brasileira como ferramenta de política pública para inclusão digital: o middleware Ginga à provação da justiça social. Revista Crítica y Emancipación, Ano VII, n. 13 Buenos Aires, Primer Semestre 2015.

LEAL, S. A. G.; MARTINS, A. B. N. ; CONDE, L. A colocada em tecnologia de problemas sociais: aplicativo Brasil 4D à provação da justiça social e da justiça cognitiva. In: Las encrucijadas abiertas de América Latina. La sociología en tiempos de cambio. Buenos Aires: ALAS, 2017. v. 23. p. 1-23.

A colocada em tecnologia de problemas sociais: aplicativo Brasil 4D à provação da justiça social e cognitiva. Montevideo: XXXI Congresso da Associação Latino-Americana de Sociologia (Alas), 2017. Disponível em: <http://www.alas2017.com/ponencias-completas/>. Acessado em: 18 Jan. 2019.

LOZANO, Fernando Silva; COSTA, Heitor Augustus Xavier. O movimento pelo software livre e a plataforma Java. Bazar: Software e Conhecimento Livres, n. 1, p. 33-46, Jul. 2006.

MALLARD, Alexandre. L'écriture des normes. Réseaux, v. 18, n. 102, p. 37-61, 2000. Disponível em: <http://www.persee.fr/web/revues/home/prescript/article/ reso_07517971_2000_num_18_102_2257>. Consultado em: 19 Fev. 2014.

MAURíCIO, Patrícia. Conflitos na TV digital brasileira. Rio de Janeiro: Editora PUC/ Rio - Apicuri, 2012.

MITCHELL, Timothy. Rule of experts: Egypt, techno-politics, modernity. Berkeley (CA): The University of California Press, 2002.

SILVA, Juliano Domingues. A política da política de TV digital no Brasil: atores, interesses e decisão governamental. Rio de Janeiro: Luminária Academia, 2011.

SOUJAVA. Ginga-J: abaixo assinado a favor de java e ginga-j no padrão brasileiro de TV digital. In: SouJava, 5 de junho de 2012. Disponível em: <https://soujava.org.br/ servicos/abaixo-assinado-ginga-j/>. Acesso em: 10 Maio 2014. 
STAR, Susan Leigh; GRIESEMER, James. Institutional ecology, "translations" and boundary objects: amateurs and professionals in Berkeley's Museum of Vertebrate Zoology, 1907-1939. Social Studies of Science, v. 19, p. 387-420. London: Sage, 1989.

SUN MICROSYSTEMS. Java technologies for interactive television (technical white paper). California, 2001. Disponível em: <http://www.oracle.com/technetwork/ java/javame/techintertv052101-150048.pdf>. Consultado em: 11 Jan. 2014.

VARGAS, Eduardo; LEAL, Sayonara. Démocratie technologique et innovation dans les services: une analyse socio-technique de la définition de la norme de la télévision numérique au Brésil. Revue Économies et Sociétés, Paris, 2011.

TAKHTEYEV, Y. Coding places: software practice in a South American city. Cambridge (Ma): MIT Press, 2012.

THEVENOT, L. Un gouvernement par les normes; pratiques et politiques des formats d'information. In: CONEIN, B.; THÉVENOT, L. (Dirs.). Cognition et information en société, p. 205-241. Paris: Éditions de L'École des Hautes Études en Sciences Sociales, 1997.

VARGAS, Eduardo; LEAL,Sayonara. Democracia técnica e lógicas de ação: uma análise sociotécnica da controvérsia em torno da definição do Sistema Brasileiro de Televisão Digital -SBTVD. Revista Sociedade e Estado, v. 26, n. 2, Maio/Ago. 2011.

VEIGA, Welington; CAMPOS, Fernanda; DAVID, José Maria: BRAGA, Regina. Uma abordagem de ecossistemas de software para o domínio de e-learning. Paper apresentado no XII Brazilian Symposium on Information Systems. Florianópolis (SC), 2016.

ZELIZER, Viviana. A negociação da intimidade. Petrópolis: Vozes, 2011. 